\title{
THE ANTIDEPRESSANT DRUG DOXEPIN: A PROMISING ANTIOXIDANT
}

\section{SHAUROSENI PALCHOUDHURI ${ }^{1}$, DEBANJAN MUKHOPADHYAY ${ }^{2}$, DEBALINA SINHA ROY ${ }^{1}$, BIDISHA GHOSH ${ }^{3}$, SUKHEN DAS ${ }^{3}$, SUJATA G DASTIDAR ${ }^{1 *}$}

${ }^{1}$ Department of Micrbiology, Herbicure Healthcare Bio-Herbal Research Foundation, Saraldighi (E), Kolkata, West Bengal, India. ${ }^{2}$ Department of Pathology, Microbiology and Immunology, School of Veterinary Medicine, University of California, Davis, CA, USA. ${ }^{3}$ Department of Physics, Jadavpur University, Kolkata, West Bengal, India. Email: jumicrobiol@yahoo.co.in

Received: 11 September 2016, Revised and Accepted: 23 November 2016

\section{ABSTRACT}

Objective: Oxidative stress contributes to the pathophysiology of exposure to environmental pollutants and to different free radical generating biochemical reactions in a human system leading to various types of age-related ailments. An antioxidant is a substance capable of preventing or slowing down oxidation of other molecules. Administration of different natural or synthetic antioxidants can ably lead to prevention and attenuation of such stress-induced biochemical alterations. Best examples of natural antioxidants are plant-derived flavonoids. The present study has been designated to determine antioxidant properties in antidepressant compound doxepin which is structurally similar to flavonoid quercetin.

Methods: Antioxidant capacity in doxepin was determined with help of several standard conventional procedures such as phosphomolybdenum assay, Ferric ion and cupric ion reducing power assays, ferrous ion chelating activity assay, hydrogen peroxide, and nitric oxide scavenging activity assays.

Results: Doxepin showed a stable rise in its antioxidant activity in a dose-dependent manner as determined by ferric as well as cupric ion reducing capacity and by phosphomolybdenum assay. An almost identical observation was noted while determining ferrous ion chelating activity. Furthermore, doxepin showed a strong nitric oxide scavenging activity in all the concentrations used in the study while its hydrogen peroxide scavenging activity was only observed at $500 \mu \mathrm{g} / \mathrm{ml}$ of doxepin.

Conclusion: Thus, our study opens up a new vista in search for antioxidants not only from plant sources but also from clinically established pharmaceutical compounds that are already in practical use among patients.

Keywords: Antioxidant, Antidepressant, Doxepin, Quercetin, Flavanol, Flavonoids.

(c) 2017 The Authors. Published by Innovare Academic Sciences Pvt Ltd. This is an open access article under the CC BY license (http://creativecommons. org/licenses/by/4. 0/) DOI: http://dx.doi.org/10.22159/ajpcr.2017.v10i3.15149

\section{INTRODUCTION}

The driving forces to sustain life are some of the processes of biochemical reactions which continue till death of human beings. Such incessant processes in our bodies generate several bio-molecules, of which some are reactive oxygen species (ROSs) and free radicals [1]. Occupational exposure to environmental pollutants such as pesticides, toxic chemical wastes, direct as well as indirect cigarette smoke, gasoline exhaust, urban air pollutants ozone and radiation, and physical stress have been demonstrated to produce similar reactive molecular species in our bodies [2]. These molecules cause oxidative degradation of lipids, proteins, and DNA, activation of procarcinogens, inhibition of cellular and antioxidant defense system, depletion of sulfhydryls, altered calcium homeostasis, changes in gene expression, and induction of abnormal proteins and contribute significantly to human disease pathophysiology [3-5]. Certain substances known as antioxidants act as preventive oxidants caused by such free radicals and ROS. Halliwell [6] defined antioxidants as "any substance that delays, prevents or removes oxidative damage to a target molecule." The antioxidant vitamins such as vitamins $\mathrm{C}$ and $\mathrm{E}, \mathrm{B}$-carotene and proanthocyanidins, antioxidant minerals such as zinc and selenium, and antioxidant enzymes such as glutathione, superoxide dismutase, and catalase, have been vividly studied for their potential role in the prevention of degenerative diseases including tumor growth and carcinogenesis [5-8]. Research evidence has suggested a link between increased levels of ROS and disturbed activities of enzymatic and nonenzymatic antioxidants in diseases associated with aging [9].
Through several studies, the different modes of action of various antioxidants have been observed: As preventers of oxidation reactions caused by free radicals, free lipid radical formation inhibitors, by breaking the chain of auto-oxidation reactions, as quenchers of singlet oxygen, by converting the hydroperoxides through reduction and the metal pro-oxidants by chelating metals into stable compounds, and finally as inhibitors of pro-oxidative enzymes [10-14].

Flavonoids are a class of naturally occurring polyphenolic compounds, isolated from a wide range of vascular plants. They generally occur in plants as glycosylated derivatives, and they contribute to the brilliant shades of blue, scarlet, and orange, in leaves, flowers, and fruits. Apart from various vegetables and fruits, flavonoids are found in seeds, nuts, grains, spices, and different medicinal plants as well in beverages, such as wine particularly red wine, tea, and at lower levels in beer [15]. The basic flavonoid structure is the flavan nucleus, which consists of 15 carbon atoms arranged in three rings. Different biological activities of flavonoids had been the subject of several studies in the past years, and it has been revealed that they exhibit antimicrobial, antiallergenic, antiviral, anti-inflammatory, and vasodilating actions. However, most interests have been devoted to the antioxidant activity of flavonoids, which is due to their ability to reduce free radical formation and to scavenge free radicals [16].

Among the flavonol subclass of flavonoids, quercetin is a major representative. Quercetin is the flavonoid widely distributed in nature and is one of the most abundant dietary flavonoids with an average 
daily consumption of $25-50 \mathrm{mg}$. Quercetin has been observed to act mainly in the prevention of oxidation of low-density lipoproteins by scavenging free radicals and chelating transition metal ions [17].

A large number of studies by different workers from several parts of the world have repeatedly provided enough evidence that pharmaceutical compounds synthesized for a particular pharmacological action often simultaneously possess some other function equally efficiently [18-21].

Such observations have repetitively proved that multiplicity of function in chemically synthesized drugs is a rule rather than an exception. With this background, the structural similarity of the synthetic antidepressant compound doxepin with the known antioxidant quercetin has replenished sufficient evidence to explore antioxidant action in this drug. Moreover, there is hardly any synthetic antidepressant available in the market for human consumption except the vitamins. The present study was therefore designed to carry out an elaborate experimental work to prove the efficacy of doxepin as an antioxidant with the help of a number of known standard tests.

\section{METHODS}

\section{Drug}

Doxepin was obtained as pure dry powder from Sigma-Aldrich, USA. It was preserved at $4^{\circ} \mathrm{C}$. The drug powder was soluble in water.

\section{Chemicals and reagents}

All the chemicals and reagents used in the following different assays were purchased from Loba Chemie (Mumbai, India), Sisco Research Laboratory (SRL, Mumbai, India), Merck (Bengaluru, India), and from HiMedia (Mumbai, India). They were all of analytical grade.

\section{Preparation of the sample}

For every analysis, a freshly prepared working solution of $1 \mathrm{mg} / \mathrm{ml}$ of the drug powder was prepared by dissolving in Milli-Q grade water.

\section{Protocols for detection of in vitro antioxidant and free radical scavenging activity}

\section{Total antioxidant capacity determination}

The phosphomolybdenum method as described by Prieto et al. [22] was followed for the estimation of total antioxidant capacity. This assay is based on the principle of reduction of Mo (VI) to Mo (V) by an agent and subsequent formation of a green phosphate/Mo (V) complex at acidic $\mathrm{pH}$. Tubes containing $0.2 \mathrm{ml}$ aliquots of concentrations 25, 50, 100, 200, and $500 \mu \mathrm{g} / \mathrm{ml}$ of the drug solution were mixed with $1.8 \mathrm{ml}$ of distilled water and $2 \mathrm{ml}$ of phosphomolybdenum reagent $(0.31 \mathrm{M}$ sulfuric acid, $2 \mathrm{mM}$ sodium phosphate, and $4 \mathrm{mM}$ ammonium molybdate). The amount of $0.2 \mathrm{ml}$ of water was used instead of doxepin as the control. All of the tubes were then incubated in a water bath set at $95^{\circ} \mathrm{C}$ for 90 minutes. After cooling to room temperature, absorbances were measured at $695 \mathrm{~nm}$ using a ultraviolet-visible (UV-VIS) spectrophotometer (Evolution 201, Thermo Scientific) against the blank. A standard curve was prepared using different concentrations of ascorbic acid $(1000,500,250$, $125,62.5$, and $31.25 \mu \mathrm{g} / \mathrm{ml})$. The total antioxidant activity is expressed as the $\mu \mathrm{g} / \mathrm{ml}$ equivalents of ascorbic acid, defined as ascorbic acid equivalent activity and calculated as $\%$ of inhibition $=\left(A_{0}-A_{1}\right) / A_{0} \times 100$, where $A_{0}$ is the absorbance of the control (blank, without drug) and $A_{1}$ is the absorbance of the different drug solutions.

\section{Ferric ion reducing capacity determination}

This assay was performed by following the method as described by Prieto et al. [22]. Accordingly, $0.1 \mathrm{ml}$ aliquots of different concentration of the sample solution $(25 \mu \mathrm{g} / \mathrm{ml}, 50 \mu \mathrm{g} / \mathrm{ml}, 100 \mu \mathrm{g} / \mathrm{ml}, 200 \mu \mathrm{g} / \mathrm{ml}, 500 \mu \mathrm{g} / \mathrm{ml})$ were taken in different tubes and to each one of them $0.5 \mathrm{ml}$ of deionized water and $0.09 \mathrm{ml}$ of $95 \%$ ethanol were added. Subsequently, further addition of each of $0.15 \mathrm{ml}$ each of $1 \mathrm{M} \mathrm{HCl}, 1 \%$ potassium ferrocyanide, $0.05 \mathrm{ml}$ of $1 \%$ sodium dodecyl sulfate, and $0.1 \mathrm{ml}$ of $0.2 \%$ ferric chloride were followed. The tubes were then vortexed properly, and readings were taken at $700 \mathrm{~nm}$ in a spectrophotometer (Evolution 201, Thermo
Fisher) against the blank. Potent antioxidants reduce $\mathrm{Fe}^{3+}$ ions to $\mathrm{Fe}^{2+}$ which forms a Prussian blue colored complex with the ferrocyanide. The intensity of the Prussian blue color in the reaction tubes as measured at the said wavelength monitors the amount of the $\mathrm{Fe}^{2+}$ ions generated. Thus, a higher ferric ion reducing power was indicated by a greater absorbance. A standard curve was prepared by different concentrations of ascorbic acid $(1000,500,250,125,62.5$ and $31.25 \mu \mathrm{g} / \mathrm{ml})$.

\section{Cupric ion reducing capacity determination}

For this assay, the protocol as described by Apak et al. [23] was followed. The basic principle is based on the measurement of absorbance at $450 \mathrm{~nm}$ by the formation of stable colored complex between neocuproine and copper (I). Copper (II)-neocuproine $(\mathrm{Cu}[\mathrm{II}]-\mathrm{Nc})$ reagent is utilized as the oxidizing agent for the reaction. As for the purpose, $0.6 \mathrm{ml}$ volume each of double distilled water, cupric chloride $(0.01 \mathrm{M})$, and sodium citrate $(25 \% \mathrm{w} / \mathrm{v})$ were added to correctly labeled tubes and shaked vigorously for proper mixing. This was followed by the addition of $0.6 \mathrm{ml}$ volume of sample solution in increasing concentrations $(25,50,100,200$, and $500 \mu \mathrm{g} / \mathrm{ml})$ to each of the respective tubes. Finally, $0.6 \mathrm{ml}$ neocuproine $(0.0075 \mathrm{M})$ was added to all of them and then the reaction mixtures were incubated at room temperature for 30 minutes. Absorbances were taken at $450 \mathrm{~nm}$ using a UV-VIS spectrophotometer (Evolution 201, Thermo Scientific) against the blank. A standard curve was prepared by different concentrations of ascorbic acid (1000, 500, 250, 125, 62.5, and $31.25 \mu \mathrm{g} / \mathrm{ml})$. The results are expressed as $\mu \mathrm{g} / \mathrm{ml}$ equivalents of ascorbic acid.

\section{Ferrous ion chelating activity determination}

The standard method as described by [24] was followed for the estimation of ferrous ion chelating ability of the drug doxepin. The basic principle of this assay is that ferrozine, which initiates the reaction by combining with divalent iron to form a stable magenta complex species, the absorbance of which is measured at $562 \mathrm{~nm}$. In the presence of potent metal ion chelators, the ferrozine- $\mathrm{Fe}^{2+}$ complex formation is interrupted as they compete with ferrozine in chelating the ferrous ions. Briefly, to $3 \mathrm{ml}$ of different concentrations of the drug solution $(25,50,100,200,500 \mu \mathrm{g} / \mathrm{ml}), 0.15 \mathrm{ml}$ of $2 \mathrm{mM} \mathrm{FeCl}_{2}$ was added. The reaction was then initiated by the addition of $0.3 \mathrm{ml}$ of $5 \mathrm{mM}$ ferrozine into the mixture and incubated at room temperature for 10 minutes. Finally, the absorbance of the ferrozine-ferrous ion complex was read at $562 \mathrm{~nm}$ against the blank. Ethylene diamino tetra acetate was used as the positive control for this assay. The chelating activity of the drug was calculated as ferrous ion chelating ability in $\%=(1-[$ test sample absorbance/blank sample absorbance]) $\times 100 \%$.

\section{Hydrogen peroxide scavenging activity determination}

Although hydrogen peroxide is not a free radical, in physiological system, it forms complexes with metals such as iron and copper and reacts to produce highly reactive hydroxyl radicals which are extremely toxic to the living tissues [25]. According to the modified method of determining hydrogen peroxide scavenging activity by Mukhopadhyay et al. [26], $1.5 \mathrm{ml}$ of different concentrations of the drug solution $(25,50,100,200,500 \mu \mathrm{g} / \mathrm{ml})$ were added to $0.25 \mathrm{ml}$ of $1 \mathrm{mM}$ ferrous ammonium sulfate and mixed and then to each tube, $62.5 \mu \mathrm{L}$ of $5 \mathrm{mM}$ hydrogen peroxide were added, and all of them were then incubated for 5 minutes at room temperature in dark. Following the incubation, $1.5 \mathrm{ml}$ volume of 1,10-phenanthroline monohydrate was pipetted into the reaction mixtures and again kept for 1 minute in dark at room temperature. After that, absorbances were measured at $510 \mathrm{~nm}$ using a UV-VIS spectrophotometer (Evolution 201, Thermo Scientific) against the blank. Ascorbic acid was used as the reference standard of the assay. The percentage of hydrogen peroxide scavenging activity of the drug was calculated as given below:

$\%$ of scavenging activity $=\left(A_{\text {test }}-A_{\text {blank }}\right) \times 100$.

Where $A_{\text {blank }}$ is the absorbance of solution containing only ferrous ammonium sulfate and 1,10-phenanthroline and $A_{\text {test }}$ is the absorbance 
of the solution containing ferrous ammonium sulfate, hydrogen peroxide, 1,10-phenanthroline and along with test compound having expected hydrogen peroxide scavenging activity.

\section{Nitric oxide scavenging activity determination}

Chronic physiological generation of nitric oxide leads to a number of significant toxic effects including vascular collapse with septic shock, and it also plays a key role in inflammatory conditions such as juvenile diabetes, multiple sclerosis, arthritis, and ulcerative colitis [27]. For the assay to estimate the nitric oxide scavenging activity of antioxidants, the method as described by Chaudhuri et al. [28] was followed. Here, sodium nitroprusside is used as the nitric oxide donor, which when generated in the system interacts with oxygen to form the highly reactive peroxynitrite anion ( $\mathrm{ONOO}^{-}$), and this can be measured by Griess-Illosvoy reaction [29]. As per the protocol, $1 \mathrm{ml}$ of different concentrations of doxepin $(25,50$, 100,200 , and $500 \mu \mathrm{g} / \mathrm{ml}$ ) was added in tubes to which $1 \mathrm{ml}$ of $10 \mathrm{mM}$ sodium nitroprusside was given and mixed properly. This was followed by incubation for $3 \mathrm{hrs}$ at room temperature. After this, $1 \mathrm{ml}$ of Griess reagent $\mathrm{A}(1 \% \mathrm{w} / \mathrm{v}$ sulfanilamide) was pipetted into each of the tubes, and again they were incubated for 20 minutes at $30^{\circ} \mathrm{C}$. Finally, the assay is completed with the addition of $1 \mathrm{ml}$ of Griess reagent B $(0.1 \% \mathrm{w} / \mathrm{v}$ naphthylethylenediamine dihydrochloride or NED) to the mixture tubes and again incubated for 10 minutes in dark at room temperature. Absorbances were recorded at $546 \mathrm{~nm}$ using a UV-VIS spectrophotometer (Evolution 201, Thermo Scientific) against the blank. Ascorbic acid was used as the positive control. The percentage of nitric oxide radical scavenging activity of the drug solutions was calculated as given below:

$\%$ of scavenging activity=(absorbance of control-Absorbance of test/Absorbance of control) $\times 100$.

\section{Statistical analyses}

Statistical analysis was done using One way Anova following Bonferoni post hoc test (GraphPad Prism version 5.0 software).

\section{RESULTS}

Determination of totalantioxidantactivity by phosphomolybdenum assay

Our result indicates in an increasing trend of total antioxidant activity with increase in concentration of the antidepressant compound ranging from $25 \mu \mathrm{g} / \mathrm{ml}$ to $500 \mu \mathrm{g} / \mathrm{ml}$. The obtained average angular error (AAE) values have been depicted in the graph (Fig. 1) against the different concentrations of doxepin. From the bar diagram, it can be observed that doxepin has a moderately high molybdenum ion reducing ability with the values ranging from $25.3 \pm 1.47 \mathrm{AAE}$ at $25 \mu \mathrm{g} / \mathrm{ml}$ and reaching its maximum to $174.35 \pm 8.39 \mathrm{AAE}$ at $500 \mu \mathrm{g} / \mathrm{ml}$.

\section{Detection of ferric ion reducing activity in doxepin}

Researchers worldwide have studied that compounds which have potent reducing power can act as electron donors and also can reduce the oxidized intermediates. This is a measure of significant antioxidant potentiality of a compound [30,31]. Observations from this experiment indicate that there is a positive increase in the ferric ion reducing ability of doxepin with its increasing concentration (Fig. 2). The ascorbic acid equivalent values ranged from $7.69 \pm 3.77 \mathrm{AAE}$ at $25 \mu \mathrm{g} / \mathrm{ml}$ and reaching its maximum to $22.86 \pm 5.66 \mathrm{AAE}$ at $500 \mu \mathrm{g} / \mathrm{ml}$ of the drug.

\section{Evaluation of cupric ion reducing activity}

Molecules having antioxidant capacities, specially belonging to the class of hydroxyl radicals of phenolic compounds, have the ability to reduce $\mathrm{Cu}^{2+}$ ions to $\mathrm{Cu}^{+}$. These $\mathrm{Cu}^{+}$ions generated in the system, then react and form the colored complex with neocuproine whose absorbance is measured at the said wavelength [23]. Doxepin exhibited increased reduction of $\mathrm{Cu}^{2+}$ ion to $\mathrm{Cu}^{+}$with increasing concentrations of the drug. However, its cupric ion reducing ability is much lower in comparison with other scavenging or reducing abilities, as shown by the observations, ranging from $2.54 \pm 0.75 \mathrm{AAE}$ at $25 \mu \mathrm{g} / \mathrm{ml}$, and reaching its maximum to $6.5 \pm 1.11 \mathrm{AAE}$ at $500 \mu \mathrm{g} / \mathrm{ml}$.

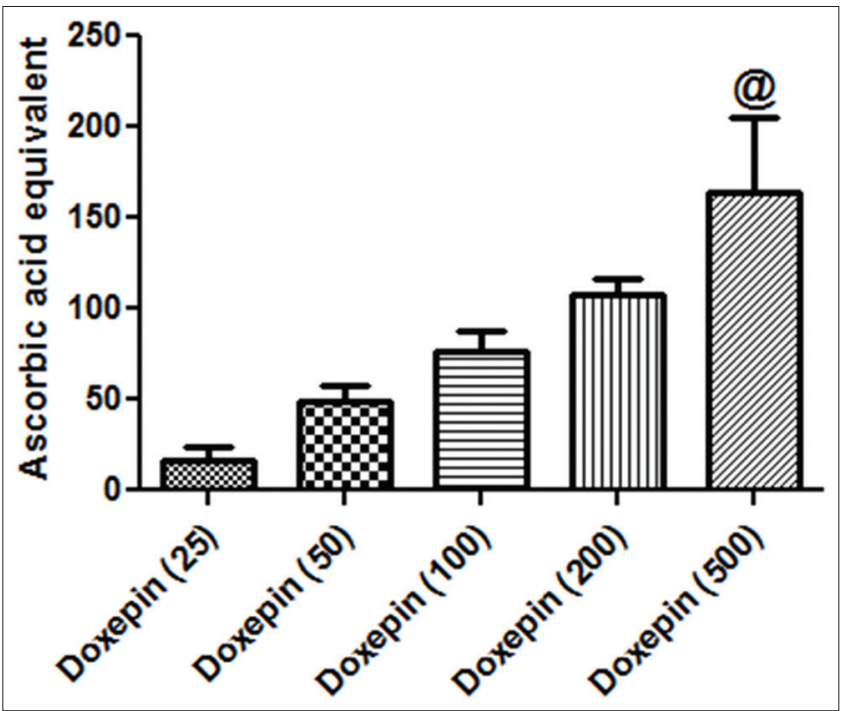

Fig. 1: The total antioxidant activity of doxepin by the phosphomolybdenum assay where the $\mathrm{X}$-axis denotes the different concentration of the drug $(\mu \mathrm{g} / \mathrm{ml})$.*@ means $\mathbf{p}<0.01$, compared to Doxepin (25) and Doxepin (50). The assay was repeated three times $(n=3)$. Values are expressed as mean \pm standard deviation

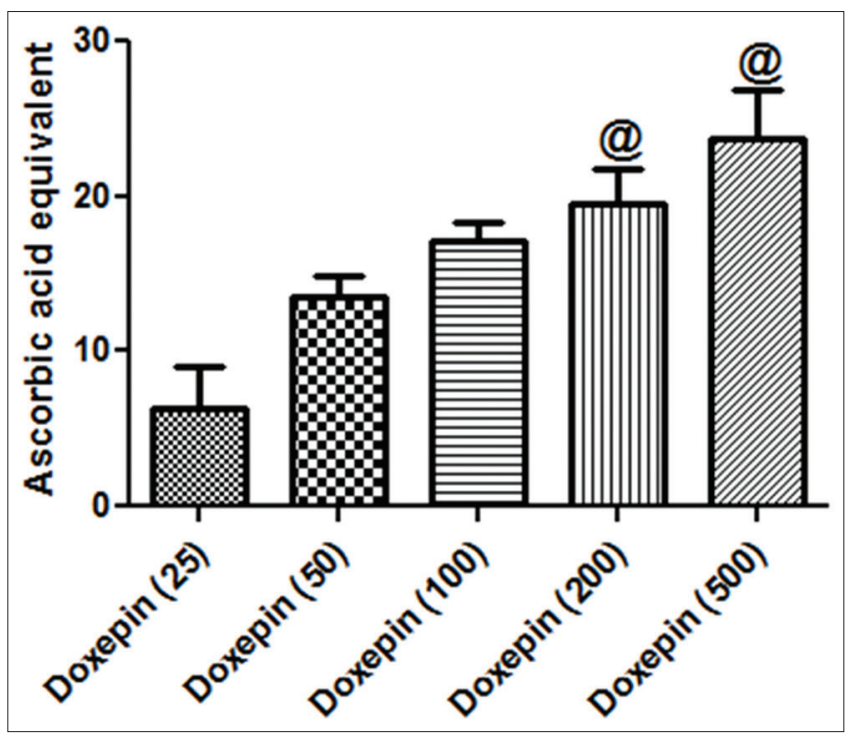

Fig. 2: The ferric ion reducing activity of doxepin by the ferric reducing antioxidant power assay where the $\mathrm{X}$-axis denotes the different concentration of the drug $(\mu \mathrm{g} / \mathrm{ml})$. *@ means $\mathbf{p}<0.01$, compared to Doxepin (25). The assay was repeated three times

$(n=3)$. Values are expressed as mean \pm standard deviation

\section{Action of doxepin on ferrous ion chelating property}

The chelating activity of the drug was estimated on the basis of the measurement of color reduction of the ferrozine - $\mathrm{Fe}^{2+}$ complex. As transition metal ions such as $\mathrm{Fe}^{2+}$ can move single electrons which result in the formation and propagation of many radical reactions, the ability to chelate them is considered to be a significant measurement of a compound's antioxidant capacity [32]. Our study shows that doxepin was able to potentially chelate the metal ion which increased in a dose-dependent manner. The percentage of scavenging activity was calculated and plotted against the different concentrations of the drug (Fig. 3). The values of the activity percentage varied between $4.88 \pm 1.05 \%$ at $25 \mu \mathrm{g} / \mathrm{ml}$ and $35.53 \pm 1.55 \%$ at $500 \mu \mathrm{g} / \mathrm{ml}$. 
Effect of doxepin on hydrogen peroxide scavenging property As mentioned earlier, hydrogen peroxide although a weak oxidizing agent, but it can further generate toxic hydroxyl radical in living systems. Following the protocol as described by Mukhopadhy et al. [26], the percentage of hydrogen peroxide scavenging activity of doxepin was calculated and it was plotted against the different concentrations of the drug (Fig. 4). As from the figure, it can be observed that in all the concentrations used in the study, doxepin showed $20-30 \%$ of hydrogen peroxide scavenging activity.

\section{Determination of nitric oxide scavenging activity of doxepin} Studies from several researches have revealed that nitric oxide is an important free radical which has a key role in generating toxic inflammatory processes in the physiological system. Our experiment proves that doxepin significantly inhibits nitrite formation by directly competing with oxygen to react with nitric oxide. As observed from Fig. 5, in all the concentrations, doxepin showed high levels of nitric oxide scavenging activity ranging from $50 \%$ to $70 \%$.

\section{DISCUSSION}

Recent scientific investigations throughout the world suggest that there is strong evidence of involvement of oxidative stress in the

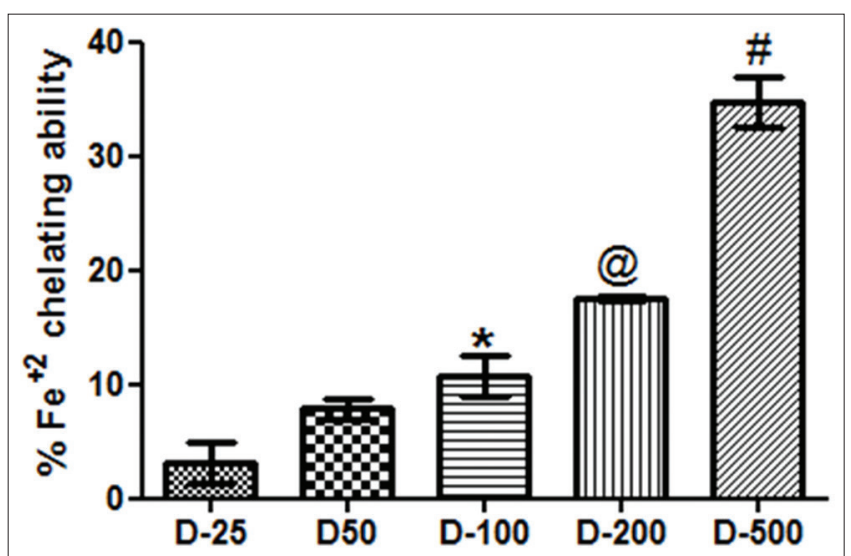

Fig. 3: Graphical representation showing the ferrous ion chelating activity of doxepin where the $\mathrm{X}$-axis denotes different concentrations of doxepin $(\mu \mathrm{g} / \mathrm{ml})$. *\# means $\mathrm{p}<0.001$, compared to rest of the concentrations; @ means p $<0.01$, compared to rest of the concentrations; * means $p<0.05$, compared to rest of the concentrations. The assay was repeated three times $(n=3)$. Values are expressed as mean \pm standard deviation

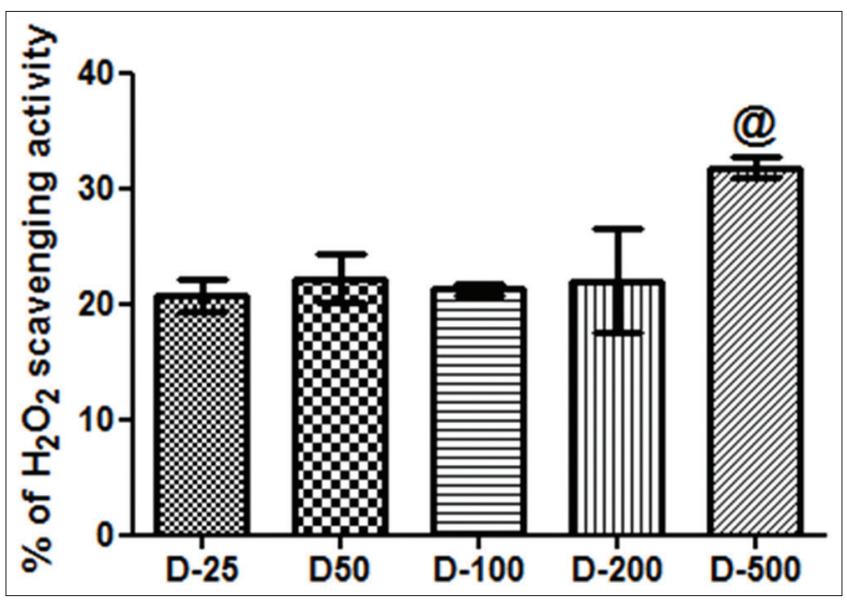

Fig. 4: Graphical representation showing the hydrogen peroxide scavenging activity of doxepin where the $\mathrm{X}$-axis denotes different concentrations of doxepin $(\mu \mathrm{g} / \mathrm{ml}) . * @$ means $\mathrm{p}<0.01$, compared to rest of the concentrations. The assay was repeated three times $(n=3)$. Values are expressed as mean \pm standard deviation pathogenesis of cancer, atherosclerosis, inflammatory diseases, and neurodegenerative disorders such as Alzheimer, parkinsonism, and convalescent. Such an oxidative stress is primarily induced by the RO which include both oxygen radical and nitric oxide radicals. However, certain non-radical derivatives of oxygen like hydrogen peroxide, hypochlorous acid, and singlet oxygen can also be involved in this process [33]. These free radicals synthesized by various biochemical reactions in the human body can cause structural and functional damage to the neurons, proteins, lipids, nucleic acids, and different cellular molecules [34]. Thus, there is an urgent need for the search of free radical scavengers or antioxidants for the prevention of such cellular damages [35]. Although most of the studies are focused either on synthesized new molecules in pharmaceutical industries or detection of antioxidants in plant products, this study has been directed to search for antioxidants among known pharmacological compounds with structural similarity with flavonoids of plant origin which possess

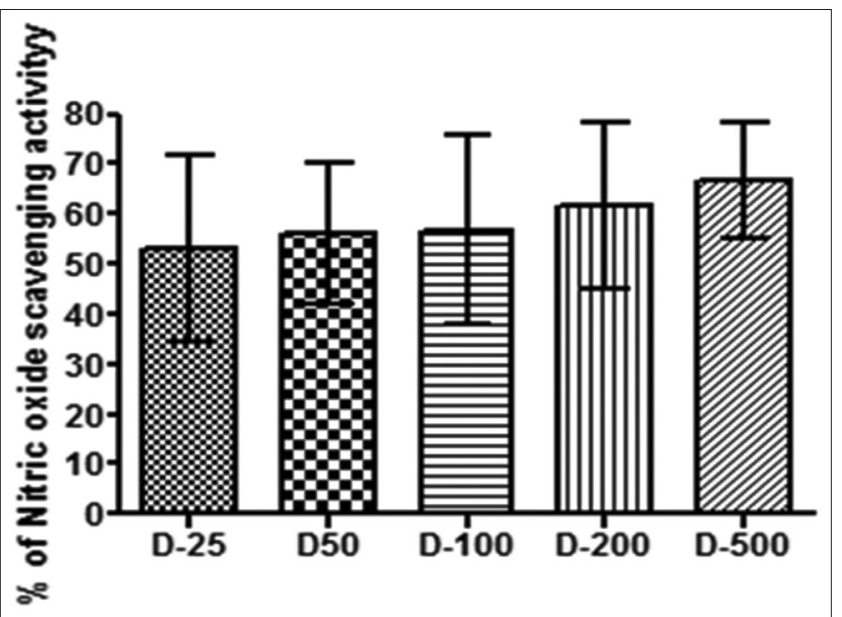

Fig. 5: Graphical representation showing the nitric oxide scavenging activity of doxepin where the $\mathrm{X}$-axis denotes different concentrations of doxepin $(\mu \mathrm{g} / \mathrm{ml})$. The assay was repeated three times $(n=3)$. Values are expressed as mean \pm standard deviation

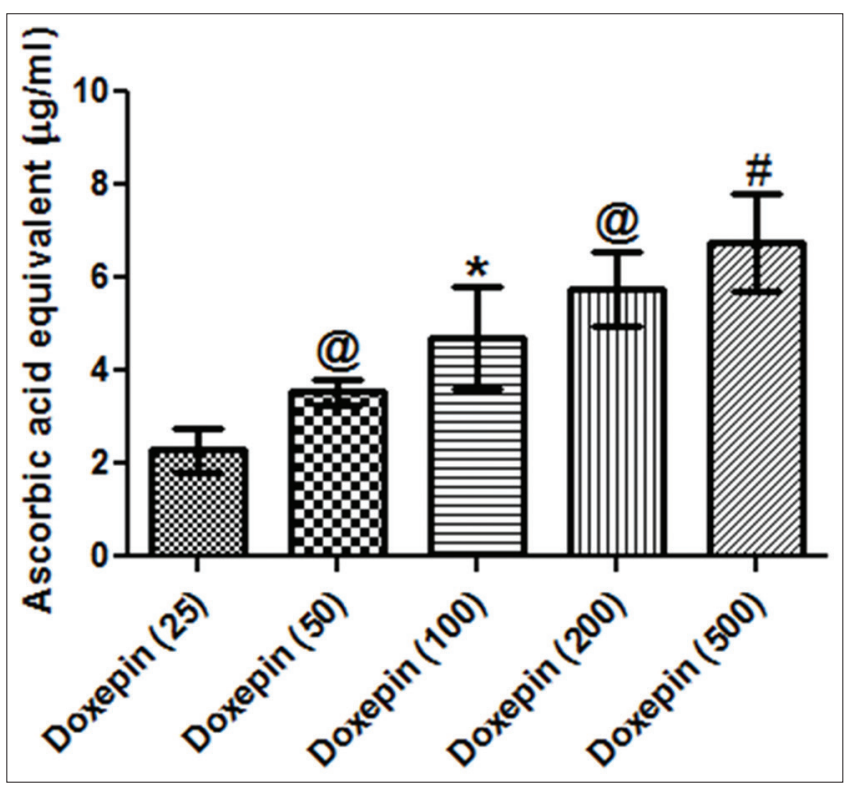

Fig. 6: The cupric ion reducing activity of doxepin by the cupric reducing antioxidant capacity assay where the $\mathrm{X}$-axis denotes the different concentration of the drug $(\mu \mathrm{g} / \mathrm{ml})$. *\# means $\mathrm{p}<0.001$, compared to Doxepin (25); @ means p<0.01, compared to rest Doxepin (200) and Doxepin (500); * Means p<0.05, compared to Doxepin (25). The assay was repeated three times $(n=3)$. Values are expressed as mean \pm standard deviation 
potent antioxidant properties [36,37]. The antidepressant drug doxepin was found to resemble structurally the plant-derived flavonoid compound quercetin.

While determining the total antioxidant activity in doxepin by phosphomolybdenum assay, it was found that there was a steady, gradual rise in the activity with the increase in the amount of the compound with respect to amino acid equivalent (Fig. 1). Again in the ferric reducing antioxidant power assay, doxepin distinctly revealed a stepwise increase in antioxidant property much like the control (Fig. 2). Subsequently by the cupric reducing antioxidant capacity assay process, doxepin showed gradually increasing reduction of $\mathrm{Cu}^{++}$ion to $\mathrm{Cu}^{+}$with elevation in the amount of doxepin (Fig. 6). In a separate study, doxepin showed definite $\mathrm{Fe}^{2+}$ chelating action whose values increased in a gradual manner from 25 to $200 \mu \mathrm{g} / \mathrm{ml}$ concentration, however, with $500 \mu \mathrm{g} / \mathrm{ml}$ of the drug, there was a very sharp rise in the values (Fig. 3). Doxepin although had shown hydrogen peroxide scavenging function, the values hardly varied between the amounts of 25 and $200 \mu \mathrm{g} / \mathrm{ml}$, a distinct rise in action was observed with $500 \mu \mathrm{g} / \mathrm{ml}$ of the drug (Fig. 4). Finally, doxepin revealed nitric oxide scavenging property, the percentage activity was $>50$ at $25 \mu \mathrm{g} / \mathrm{ml}$ of doxepin and remained almost the same up to $100 \mu \mathrm{g} / \mathrm{ml}$ of the drug. However, the values were slightly higher with $200 \mu \mathrm{g} / \mathrm{ml}$ of doxepin but sharply higher with $500 \mu \mathrm{g} / \mathrm{ml}$ of the compound.

Free radicals are known to cause oxidation of biomolecules in the human system, and antioxidant-rich diets can protect the body from free radicals [38]. Synthetic antioxidants such as butylhydroxyanisole or butylhydroxytoluene have been used to decelerate such processes. However, due to their unstable and volatile nature, scarcity of information regarding their safety, stability, and carcinogenicity these chemical compounds are still not in use in health-care systems $[38,39]$. Non-enzymatic antioxidants and antioxidant enzymes counteract the effects of ROS and RNS leading to the risk of oxidative stress [40].

The non-enzymatic antioxidants include the vitamins of which vitamin $\mathrm{C}$ and vitamin $\mathrm{E}$ are most promising agents and are in regular use. Epidemiological studies have shown that diets containing these vitamins help reduce risks of cardiovascular disease, stroke, and even cancer $[41,42]$. Both of these vitamins along with several other antioxidant vitamins are available in the market for human consumption, but there is practically no synthetic compound that can act as antioxidants. There are only a few reports on the detection of antioxidants property in synthesized chemical compounds. In 2005, Green and Ashwood reported on free radical scavenging activity of several synthetic compounds for neuroprotection in stroke in experimental animals [43]. However, preclinical studies with such compounds were neither comprehensive nor consistent. One of these compounds, tirilazad was investigated by some researchers but human trials demonstrated no effect on mortality or other outcomes in several disorders [44]. Thus, in view of inadequacy of information on possibilities of developing or obtaining synthesized antioxidants other than the vitamins doxepin was selected to determine its antioxidant potentiality on the basis of its structural similarity with quercetin, the known highly active antioxidant.

Doxepin is a pharmaceutical compound which is primarily given to patients suffering from acute mental depression and anxiety disorders. Doxepin is sometimes prescribed for patients complaining about insomnia as well. However, it has also been found to treat chronic idiopathy as the second line of treatment. Most of the above disorders are found to occur among elderly people, and doxepin is administered on a regular basis for long periods. Therefore, the patients who are on a regular intake of doxepin are likely to be benefitted to have an antioxidant simultaneously. A recent study has proved the efficacy of the antidepressant antipsychotic agent imipramine to process antioxidant properties also [45].
Therefore, the concept of the presence of multiplicity of action among pharmacological compounds is being proved again. Much like imipramine, toxicity profile and human tolerance levels of doxepin are well documented. Therefore, both these two drugs can be developed further by structural modifications to produce highly active antioxidants that can be safely administered to patients of all ages and also those who have greater chances of acquiring cancer, atherosclerosis, neurodegenerative diseases, and many other serious disorders. Therefore, such investigations are likely to open up new avenues of research on detection and determination of possible antioxidants among known pharmaceutical compounds.

\section{CONCLUSION}

Human body possesses a complex system of natural enzymatic and non-enzymatic antioxidant defense mechanisms that can counteract moderate to highly toxic effects of free radicals and other oxidants that are responsible for many human diseases including cancer. In view of the necessity to discover new active antioxidants, a search was directed to find out such agents from already known pharmacological compounds. On the basis of information of the presence of powerful antioxidant function in naturally occurring flavonoids in plants, the structurally similar compound doxepin was selected, and intensive studies have confirmed doxepin to be a highly potent antioxidant. In this way, novel antioxidants can be discovered from already known pharmaceutical compounds that possess structural similarity with known antioxidants including flavonoids.

\section{REFERENCES}

1. Herman D. The free radical theory of aging. In: Pryor WA, editor. Free Radicals in Biology. New York: Academic Press; 1982. p. 255-75.

2. Ames BN. Pollution, pesticides and cancer. J AOAC Int 1992;75:1-5. Available from: http://www.heinonline.org/hol/ landingpage?handle=hein.journals/environs $16 \&$ div $=16 \& \mathrm{id}=$ \&page .

3. Kehrer JP. Free radicals as mediators of tissue injury and disease. Crit Rev Toxicol 1993;23(1):21-48.

4. Stohs SJ, Bagchi D. Oxidative mechanisms in the toxicity of metal ions. Free Radic Biol Med 1995;18(2):321-36.

5. Bagchi D, Bagchi M, Stohs SJ, Das DK, Ray SD, Kuszynski CA, et al. Free radicals and grape seed proanthocyanidin extract: Importance in human health and disease prevention. Toxicology 2000;148(2-3): 187-97.

6. Halliwell B. Biochemistry of oxidative stress. Biochem Soc Trans 2007:35:1147-50.

7. Palchoudhuri S, Roy D, Rahman KA, Roy DS, Dasgupta P, Das S, et al. Evaluation of anti-oxidant and free radical scavenging potential of Withania somnifera water extract. Int J Phytother 2016;6:1-8.

8. Halliwell B, Gutteridge JM, Cross CE. Free radicals, antioxidants, and human disease: Where are we now? J Lab Clin Med 1992;119(6):598-620.

9. Sies H, Stahl W, Sevanian A. Nutritional, dietary and postprandial oxidative stress. J Nutr 2005;135(5):969-72.

10. Darmanyan AP, Gregory DD, Guo Y, Jenks WS, Burel L, Eloy D, et al. Quenching of singlet oxygen by oxygen-and sulfur-centered radicals: Evidence for energy transfer to peroxyl radicals in solution. J Am Chem Soc 1998;120:396-403. Available from: http://www.pubs.acs.org/doi/ abs/10.1021/ja9730831.

11. Heim KE, Tagliaferro AR, Bobilya DJ. Flavonoid antioxidants: Chemistry, metabolism and structure-activity relationships. J Nutr Biochem 2002;13(10):572-84.

12. Min DB, Boff JM. Chemistry and reaction of singlet oxygen in foods. Compr Rev Food Sci Food Saf 2002;1:58-72. Available from: http://www.onlinelibrary.wiley.com/doi/10.1111/j.1541-4337.2002. tb00007.x/full.

13. Pokorny J. Are natural antioxidants better - And safer - That synthetic antioxidants? Eur J Lipid Sci Technol 2007;109:629-42. Available from: http://www.onlinelibrary.wiley.com/doi/10.1002/ejlt.200700064/ full.

14. Kancheva VD. Phenolic antioxidants - Radical-scavenging and chain breaking activity: A comparative study. Eur J Lipid Sci Technol 2009;111:1072-89. Available from: http://www.onlinelibrary.wiley. com/doi/10.1002/ejlt.200900005/full. 
15. Hollman PC, van Trijp JM, Buysman MN, van der Gaag MS, Mengelers MJ, de Vries $\mathrm{JH}$, et al. Relative bioavailability of the antioxidant flavonoid quercetin from various foods in man. FEBS Lett 1997;418(1-2):152-6.

16. Pietta PG. Flavonoids as antioxidants. J Nat Prod 2000;63(1):1035-42.

17. Murota K, Terao J. Antioxidative flavonoid quercetin: Implication of its intestinal absorption and metabolism. Arch Biochem Biophys 2003;417(1):12-7

18. Martins M, Dastidar SG, Fanning S, Kristiansen JE, Molnar J, Pagès JM, et al. Potential role of non-antibiotics (helper compounds) in the treatment of multi-drug resistant Gram negative infections: Mechanisms for their direct and indirect activities. Int $\mathrm{J}$ Antimicrob Agents 2008;31(3):198-208

19. Dastidar SG, Kristiansen JE, Molnar J, Amaral L. Role of phenothiazines and structurally similar compounds of plant origin in the fight against infections by drug resistant bacteria. Antibiotics (Basel) 2013;2(1):58-72.

20. Kristiansen JE, Dastidar SG, Palchoudhuri S, Roy DS, Das S, Hendricks $\mathrm{O}$, et al. Phenothiazines as a solution for multidrug resistant tuberculosis: From the origin to present. Int Microbiol 2015;18(1):1-12.

21. Karak P, Palchoudhuri S, Roy DS, Mookerjee M, Ghosh B, Das S, et al. Experimentally potent synergism resulting from combination of the antibiotic streptomycin with the non-antibiotic dicyclomine hydrochloride. Eur J Biomed Pharm Sci 2016;3:237-44

22. Prieto P, Pineda M, Aguilar M. Spectrophotometric quantification of antioxidant capacity through the formation of a phosphomolybdenum complex: Specific application of vitamin E. Anal Biochem 1999;269(2):337-41.

23. Apak R, Güçlü K, Ozyürek M, Bektasoglu B, Bener M. Cupric ion reducing antioxidant capacity assay for antioxidants in human serum and for hydroxyl radical scavengers. Methods Mol Biol 2010;594:215-39.

24. Mukhopadhyay D, Rahman KA, Roy D, Dasgupta P. Evaluation of in vitro antioxidant activity and phytochemical constituents of kulekhara (hygrophiliaspinosa). Int J Pharmacogn Phytochem Res 2015;7:1-7. Available from: http://www.impactfactor.org/pdf/ijppr/7/ ijppr,vol7,issue 5, article17.pdf.

25. Miller HE, Rigelhof F, Marquart L, Prakash A, Kanter M. Antioxidant content of whole grain breakfast cereals, fruits and vegetables. J Am Coll Nutr 2000;19 3 Suppl:312S-9.

26. Mukhopadhyay D, Dasgupta P, Roy DS, Palchoudhuri S, Chatterjee I, Ali $\mathrm{S}$, et al. A sensitive in vitro spectrophotometric hydrogen peroxide scavenging assay using 1,10-phenanthroline. Free Radic Antioxid 2016;6:123-31. Available from: http://www.antiox.org/sites/default/ files/10.5530fra.2016.1.15 0.pdf

27. Taylor BS, Kim YM, Wang Q, Shapiro RA, Billiar TR, Geller DA. Nitric oxide down-regulates hepatocyte-inducible nitric oxide synthase gene expression. Arch Surg 1997;132(11):1177-83

28. Chaudhuri D, Ghate NB, Sarkar R, Mandal N. Phytochemical analysis and evaluation of antioxidant and free radical scavenging activity of Withania somnifera root. Asian J Pharm Clin Res 2012;5:193-9. Available from: http://www.ajpcr.com/Vol5Suppl4/1429.pdf.

29. Mandal S, Hazra B, Sarkar R, Biswas S, Mandal N. Assessment of the antioxidant and reactive oxygen species scavenging activity of methanolic extract of Caesalpinia crista Leaf. Evid Based Complement Alternat Med 2011;2011:173768

30. Shahriar M, HossainMI, Sharmin FA, Akhter S, Haque MA,
Bhuiyan MA. In vitro antioxidant and free radical scavenging activity of Withania somnifera root. IOSR J Pharm 2013;3(2):38-47.

31. Yen GC, Chen HY. Antioxidant activity of various tea extracts in relation to their antimutagenicity. J Agric Food Chem 1995;43:27-32. Available from: http://www.pubs.acs.org/doi/abs/10.1021/jf00049a007.

32. Decker EA, Welch B. Role of ferritin as a lipid oxidation catalyst in muscle food. J Agric Food Chem 1990;38:674-7. Available from: http:// www.pubs.acs.org/doi/abs/10.1021/jf00093a019.

33. Lien AP, Hua H, Chuong PH. Free radicals, antioxidants in diseases and health. Int J Biomed Sci 2008;4(2):89-96. Available from: http://www. ijbs.org/user/contentfulltext.aspx?volumeno $=4 \&$ startpage $=89 \&$.

34. Valko M, Leibfritz D, Moncola J, Cronin MT, Mazura M, Tesler J. Free radicals and antioxidants in normal physiological functions and human disease. Int J Biochem Cell Biol 2007;39(1):44-84.

35. Jena S, Jena RC, Bhol R, Agarwal K, Sarangi A, Sahu PK, et al. A comparative study of the anti-oxidative and anti-diabetic potential of in vitro and in vivo root and leaf extracts of Withania somnifera on streptozotocin induced diabetic rats. Int $\mathrm{J}$ Pharm Pharm Sci 2016;8(10):85-91. Available from: http://www.innovareacademics.in/ journals/index.php/ijpps/article/view/8103/7391.

36. Mahapatra SK, Mookerjee M, Roy DS, Karak P, Das S, Dastidar SG. Evaluation of antimicrobial potentiality of a flavonoid isolated from the leaf of the plant Colebrookea oppositifolia. Int J Biol Pharm Res 2013;4(4):225-30. Available from: http://www.ijbpr.com/cadmin/ article/298 225-230.pdf.

37. Lavanya J, Periyar SS, Jeevitha PM, Jacintha P, Aradana M. Antioxidant and antimicrobial activity of selected medicinal plants against human oral pathogens. Int J Pharm Pharm Sci 2016;8(9):71-8. Available from: http://www.innovareacademics.in/journals/index.php/ijpps/article/ view/11989/70090

38. Bharti V, Vasudeva N, Kumar S. Antioxidant studies and antimicrobial effect of Origanum vulgare Linn in combination with standard antibiotics. Int Quat J Res Ayurveda 2014;35:71-8. Available from: https://www.ncbi.nlm.nih.gov/pmc/articles/PMC4213973.

39. Nabavi SM, Ebrahimzadeh MA, Nabavi SF, Hamidinia A, Bekhradnia AR. Determination of antioxidant activity, phenol and flavonoids content of Parrotia persica Mey. Pharm Online 2008;2:560-7.

40. Flora SJ. Structural, chemical and biological aspects of antioxidants for strategies against metal and metalloid exposure. Oxid Med Cell Longev 2008;2(4):191-206. Available from: https://www.hindawi.com/ journals/omcl/2009/873634/abs.

41. Padayatty SJ, Katz A, Wang Y, Eck P, Kwon O, Lee JH, et al. Vitamin C as an antioxidant: Evaluation of its role in disease prevention. J Am Coll Nutr 2003;22(1):18-35.

42. Traber MG, Atkinson J. Vitamin E, antioxidant and nothing more. Free Radic Biol Med 2007;43(1):4-15

43. Green AR, Ashwood T. Free radical trapping as a therapeutic approach to neuroprotection in stroke: Experimental and clinical studies with NXY-059 and free radical scavengers. Curr Drug Targets CNS Neurol Disord 2005;4(2):109-18.

44. Zhang S, Wang L, Liu M, Wu B. Tirilazad for aneurysmal subarachnoid haemorrhage. Cochrane Database Syst Rev 2010;2:CD006778.

45. Roy DS, Mukhopadhyay D, Palchoudhuri S, Ghosh B, Das S, Dastidar SG. Distinct antioxidant activity of a common antidepressant drug imipramine. Free Radic Antioxid 2016;6(2):151-4. Available from: http://www.antiox.org/sites/default/files/10.5530fra.2016.2.4.pdf. 